\title{
images
}

\section{Congenital lobar emphysema}

\author{
Suhil A. Choh, ${ }^{a}$ Naseer A. Choh, ${ }^{b}$ Majid Jehangir ${ }^{b}$
}

From the a Department of Neonatology and Pediatrics, Sheri Kashmir Institute of Medical Sciences, Soura, Srinagar and bepartment of Radiology, Government Medical College, Srinagar

Correspondence and reprints: Dr. Suhil A. Choh · House No:E-12, Cooperative Colony, Pirbagh, Hyderpora Srinagar $190014 \cdot$ suhilchoh@rediffmail.com · Accepted for publication January 2008

Ann Saudi Med 2008; 28(4): 310

A 7-month-old, previously healthy infant, a product of a non-consanguineous marriage, presented with an upper respiratory tract infection with increasing respiratory distress. The physical examination was remarkable for tachypnea, subcostal indrawing and diminished air entry on the left side. Laboratory investigations revealed hypoxemia $\left(\mathrm{PO}_{2}\right.$ of $\left.55 \mathrm{~mm} \mathrm{Hg}\right)$. A chest radiogram revealed a well-circumscribed lucent area in the left upper and midzone with a shift of the mediastinum towards the right side (Figure 1). Chest CT revealed a hyperexpanded lucent left upper lobe with an attenuated vascular markings and contralateral mediastinal shift, and compression of the left upper lobe (Figure 2). The findings were classical for congenital lobar emphysema (CLE) involving the left upper lobe.

CLE involves progressive distention of a pulmonary lobe due to a variety of causes. CLE usually presents at birth (33\%) or within the first month of life (50\%) with respiratory distress. Presentation after 6 months of age is uncommon (5\%). ${ }^{1}$ The exact cause of CLE is often difficult to determine, with no apparent cause found in $50 \%$ of cases. Pathologically two forms are recognized: hypoalveolar and polyalveolar. ${ }^{2}$ The chest radiographs reveal a radiodense lobe initially at birth that becomes progressively hyperlucent and hyperexpanded. CT of the chest reveals a hyperlucent lobe with attenuated vascular markings with contralateral mediastinal shift and compression atelectasis of the ipsilateral lung. ${ }^{3}$ This condition should not be mistaken for tension pneumothorax. Treatment is conservative for cases with minimal symptoms and consist of surgical lobectomy in severe cases (as in our case). ${ }^{2}$

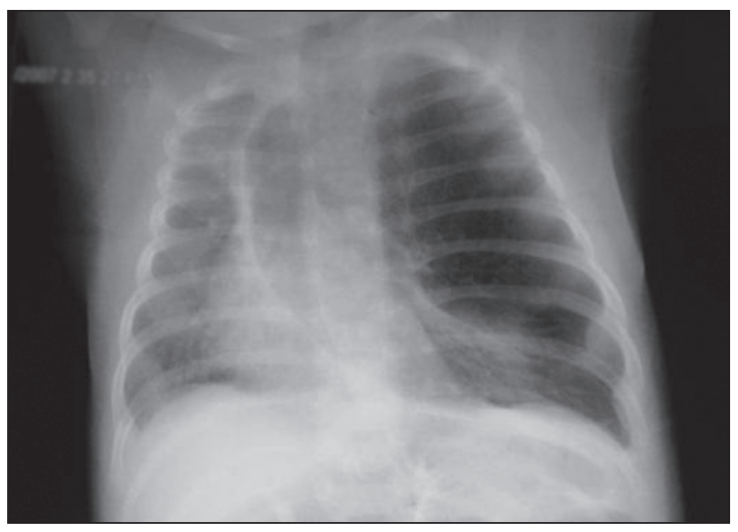

Figure 1. Anteroposterior radiograph showing hyperlucent left upper lobe with mass effect causing deviation of the mediastinum towards the right hemithorax.

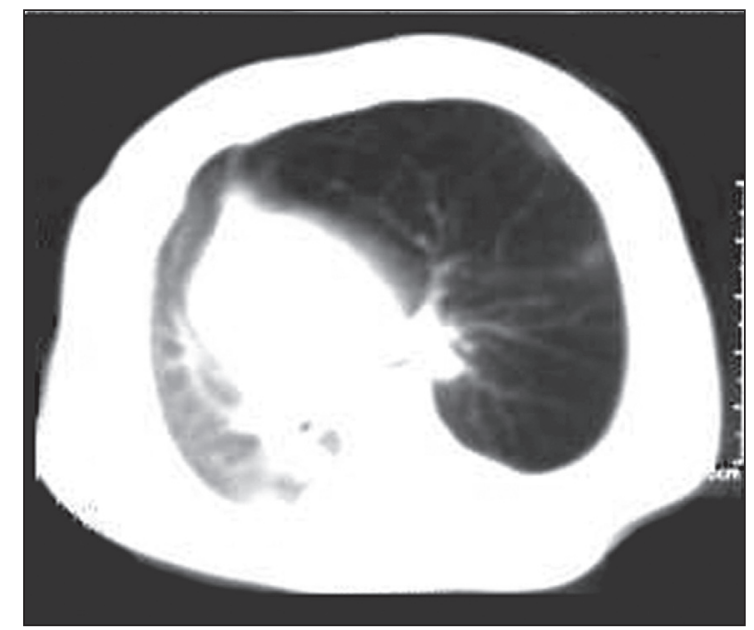

Figure 2. CT scan showing a hyperlucent and hyperexpanded left upper lobe with an attenuated but intact pattern of organized vascularity within the lobe.

\section{REFERENCES}

1. Biswal N, Mathai B, Bhatia BD, Bhat BV, Puri RK, Karthikeyan G, Bhatnagar R. Congenital lobar emphysema. Indian Pediatr 1993;30:13491354.
2. Tander B,Yalcin M,Yilmaz B,Ali Karadag C, Bulut M. Congenital lobar emphysema: a clinicopathologic evaluation of 14 cases. Eur J Pediatr Surg 2003;13(2): 108-111.
3. Daltro P, Fricke BL, Kuroki I, Domingues $R$, Donnelly LF:CT of congenital lung lesions in pediatric patients. Am J Roentgenol 2004;183(5):1497-1506. 